Int. J. Electrochem. Sci., 15 (2020) 2549 - 2560

International Journal of

ELECTROCHEMICAL

SCIENCE

www.electrochemsci.org

\title{
Biosynthesis of Ag Nanoparticle by Peganum Harmala Extract; Antimicrobial Activity and Ability for Fabrication of Quercetin Food Electrochemical Sensor
}

\author{
Bahareh Davarnia ${ }^{1}$, Seyed-Ahmad Shahidi ${ }^{1, *}$, Hassan Karimi-Maleh ${ }^{2,3,4}$, Azade Ghorbani- \\ HasanSaraei $^{1}$ and Fatemeh Karimi ${ }^{2,3}$ \\ ${ }^{1}$ Department of Food Science and Technology, Ayatollah Amoli Branch, Islamic Azad University, \\ Amol 46311-39631, Mazandaran, Iran; \\ ${ }^{2}$ School of Resources and Enviroment, University of Electronic Science and Technology of China, \\ P.O. Box 611731, Xiyuan Ave, Chengdu, P.R. China \\ ${ }^{3}$ Department of Chemical Engineering, Laboratory of Nanotechnology, Quchan University of \\ Technology, Quchan, Iran \\ ${ }^{4}$ Department of Chemical Sciences, University of Johannesburg, P.O. Box 17011, Doornfontein \\ Campus, 2028 Johannesburg, South Africa \\ *E-mail: sashahidy@yahoo.com
}

doi: $10.20964 / 2020.03 .70$

Received: 5 November 2019 / Accepted: 5 January 2020 / Published: 10 February 2020

In this study, we used Peganum harmala extract as a powerful reducing agent for biosynthesis of Ag nanoparticle (Ag-NP). The biosynthesized Ag nanoparticle was characterized using XRD and TEM methods. The results confirmed the synthesis of Ag nanoparticle with diameter $\sim 10 \mathrm{~nm}$. Then, the antibacterial activity of Ag nanoparticle was identified using Streptococcus $s p$ as Gram-positive, and $E$. coli as Gram-negative bacteria, and the results showed good antibacterial activity. In addition, the Ag nanoparticle was used for modification of carbon paste electrode (CPE) in the presence of paraffin oil (PO), and n-hexyl-3-methylimidazolium hexafluoro phosphate (MIHP) as binder. The AgNP/PO/MIHP/CPE showed a powerful catalytic activity in accelerating the electrochemical reaction of quercetin. Due to this point, it is suggested as a powerful tool for determining quercetin in the concentration ranged from 0.01 to $550 \mu \mathrm{M}$ with detection limit of $5.0 \mathrm{nM}$. The Ag-NP/PO/MIHP/CPE was successfully used for determination of quercetin in onion and hawthorn food samples.

Keywords: Extract, Quercetin Electrochemical Sensor, Ag Nanoparticle, Modified Electrode Peganum Harmala

$\underline{\text { FULL TEXT }}$ 
(C) 2020 The Authors. Published by ESG (www.electrochemsci.org). This article is an open access article distributed under the terms and conditions of the Creative Commons Attribution license (http://creativecommons.org/licenses/by/4.0/). 